\title{
Spectrophotometric determination of certain CNS stimulants in dosage forms and spiked human urine via derivatization with 2,4-Dinitrofluorobenzene
}

\author{
Mohamed I Walash, Nahed M El-Enany ${ }^{*}$ and Samar Saad
}

\begin{abstract}
A new spectrophotometric method is developed for the determination of phenylpropanolamine $\mathrm{HCl}$ (PPA), ephedrine $\mathrm{HCl}(\mathrm{EPH})$ and pseudoephedrine $\mathrm{HCl}(\mathrm{PSE})$ in pharmaceutical preparations and spiked human urine. The method involved heat-catalyzed derivatization of the three drugs with 2,4-dinitrofluorobenzene (DNFB) producing a yellow colored product peaking at $370 \mathrm{~nm}$ for PPA and $380 \mathrm{~nm}$ for EPH and PSE, respectively.

The absorbance concentration plots were rectilinear over the range of 2-20 for PPA and $1-14 \mu \mathrm{g} / \mathrm{mL}$ for both of EPH and PSE, respectively. The limit of detection (LOD) values were $0.20,0.13$ and $0.20 \mu \mathrm{g} / \mathrm{mL}$ for PPA, EPH and PSE, respectively and limit of quantitation (LOQ) values of 0.60 and 0.40 and $0.59 \mu \mathrm{g} / \mathrm{mL}$ for PPA, EPH and PSE, respectively. The analytical performance of the method was fully validated and the results were satisfactory. The proposed method was successfully applied to the determination of the three studied drugs in their commercial dosage forms including tablets, capsules and ampoules with good percentage recoveries. The proposed method was further applied for the determination of PSE in spiked human urine with a mean percentage recovery of $108.17 \pm 1.60$ for $(n=3)$. Statistical comparison of the results obtained with those of the comparison methods showed good agreement and proved that there was no significant difference in the accuracy and precision between the two methods. The mechanism of the reaction pathway was postulated.
\end{abstract}

\section{Introduction}

Phenylpropanolamine hydrochloride, (PPA) is (1RS, 2SR)2-amino-1-phenylpropanol hydrochloride [1] (Figure 1). It is a largely indirect acting sympathomimetic with an action similar to ephedrine; it is orally administered for the treatment of nasal congestion. It is frequently used in mixture preparations for the relief of cough and cold symptoms. Other uses of phenylpropanolamine include; the control of the urinary incontinence in some patients. It has also been used to suppress appetite in the management of obesity [1]. The United States Pharmacopoeia (USP) [2] and the British Pharmacopoeia (BP) [3] recommended non-aqueous titrimetric method for the determination of PPA in the pure form in presence of mercuric acetate, using perchloric acid as a titrant and crystal violet as indicator. On the other hand, USP [2] recommended HPLC method for its determination in dosage forms using

\footnotetext{
* Correspondence: nelenany1@yahoo.com

Department of Analytical Chemistry, Faculty of Pharmacy, University of Mansoura, 35516, Mansoura, Egypt
}

a mixture of (1-hexanesulfonate, monobasic sodium phosphate and triethylammonium phosphate) and methanol as a mobile phase with UV detection at $210 \mathrm{~nm}$.

Due to its clinical advantages, PPA received a great interest. A good guide to the work published is found as comprehensive monograph in analytical profiles for drugs [4]. Several analytical techniques have been reported for PPA determination either perse or in pharmaceutical preparations and biological fluids including; titrimetry [5], spectrophotometry [6], fluorimetry [7], HPLC [8], capillary electrophoresis [9], flow injection [10] and gas chromatography [11].

Ephedrine hydrochloride (EPH) is (1R, 2S)-2-(Methylamino)-1-phenylpropan-1-ol hydrochloride [1] (Figure 1). It is a sympathomimetic drug with direct and indirect effects on adrenergic receptors. It has alpha and beta-adrenergic activity and has pronounced stimulating effects on the central nervous system [1]. It is reported to reduce the viscosity of tenacious sputum and is used as an expectorant. The USP [2] recommended a non aqueous titration method for its determination in pure form in presence of mercuric 


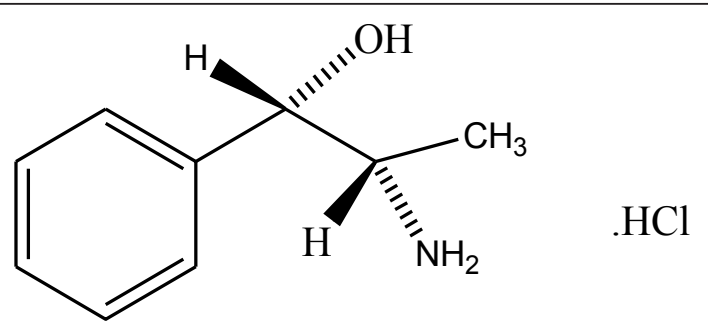

A) Phenylpropanolamine $\mathrm{HCl}$<smiles>CN[C@@H](C)[C@H](O)c1ccccc1</smiles>

B) Ephedrine $\mathrm{HCl}$<smiles>CN[C@@H](C)[C@H](O)c1ccccc1</smiles>

C) Pseudoephedrine $\mathrm{HCl}$

Figure 1 Structural formulae of the three studied drugs.

acetate and titration with $0.1 \mathrm{~N}$ perchloric acid using crystal violet as indicator. The BP [12] favored a potentiometric titration method for its determination in pure form using $0.1 \mathrm{M} \mathrm{NaOH}$ as a titrant. Both of USP and BP recommended HPLC method with UV detection at $263 \mathrm{~nm}$ for its determination in dosage forms. Various reports have been described for the analysis of EPH A good guide to the work published for EPH is found as comprehensive monograph in analytical profiles for drug substances [13]. Several techniques were reported for its determination including; titrimetry [14], spectrophotometry [15], fluorimetry [16], flow injection [17], capillary electrophoresis [18], TLC [19], HPLC [20], and gas chromatography [21].

Pseudoephedrine $\mathrm{HCl}$ (PSE) is (1S, 2S)-2-(Methylamino)-1-phenylpropan-1-ol hydrochloride [1] (Figure 1) is a direct and indirect sympathomimetic. It is a stereoisomer of ephedrine and has a similar action, but has been stated to have less pressor activity and fewer CNS effects. It is given orally for the relief of nasal congestion. They are commonly combined with other ingredients for the relief of cough and cold symptoms [1]. Also the USP [2] recommended a non aqueous titration method for the determination of PSE in its pure form in presence of mercuric acetate and titration with $0.1 \mathrm{M}$ perchloric acid using crystal violet as indicator. The BP [12] preferred a potentiometric titration for its determination in pure form using $0.1 \mathrm{M} \mathrm{NaOH}$ as a titrant. Both USP and BP recommended HPLC method with UV detection at 254 $\mathrm{nm}$ and $258 \mathrm{~nm}$, respectively, for its determination in dosage forms.

A good guide to the work published for PSE is found as comprehensive monograph in analytical profiles for drugs [22]. The literature revealed that the analysis of PSE was through techniques such as; spectrophotometry [23], flow injection [24], capillary electrophoresis [25], HPTLC [26] and HPLC [27]. 
Sanger's reagent (DNFB), on the other hand, has been utilized as a chromogen for the spectrophotometric estimation of many compounds of pharmaceutical interest such as desloratadine [28], enalapril [29], lisinopril [30] and gabapentin [31].

\section{Experimental}

\subsection{Instruments}

- A shimadzu UV-Visible 1601 PC spectrophotometer (Kyoto, Japan) was used for spectrophotometric measurements (P/N 206-67001). The recording range was 0-1.2

- A consort NV P901 digital pH Meter (Belgium) calibrated with standard buffers was used for checking the $\mathrm{pH}$ of the buffer solutions used.

- Sigma laborzentrifugen (2-16p) Centrifuge (Germany).

\subsection{Materials and Solutions}

All the reagents used were of Analytical Grade and distilled water was used throughout the work.

-Phenylpropanolamine $\mathrm{HCl}$, batch \# 41204 and ephedrine $\mathrm{HCl}$, batch \#135705, were kindly supplied from Egyptian Pharmaceutical Industries CO. E.P.I.CO $\left(10^{\text {th }}\right.$ of Ramadan-Egypt) with purity of $100.55 \%$ and $100.99 \%$ for PPA and EPH, respectively as determined by the official method [12].

-Pseudoephedrine $\mathrm{HCl}$, batch \# 050727 was kindly provided from Sigma Company, its purity was 99.65\% which was determined according to official method [12].

-2, 4 dinitrofluorobenzene (DNFB) (Fluka Chemie, Germany) was freshly prepared as $0.3 \%(\mathrm{v} / \mathrm{v})$ methanolic solution.

-Borate buffer solution ( $0.2 \mathrm{M})$ was prepared by mixing appropriate volumes of $0.2 \mathrm{M}$ boric acid and $0.2 \mathrm{M}$ $\mathrm{NaOH}$ and adjusting the $\mathrm{pH}$ using a $\mathrm{pH}$ Meter. The buffer solution was kept in the refrigerator and left to reach the room temperature before use.

-Methanol, hydrochloric acid (32\%), boric acid and tween-80 were purchased from (BDH, UK).

-Cetyltrimethylammonium bromide (cetrimide) was obtained from Merck (Darmstadt, Germany), 1\%, (w/v) aqueous solution was prepared.

-Sodium dodecyl sulphate (SDS) 95\% was obtained from Winlab (Middlesex, England), 1\%, (w/v) aqueous solution was used.

-Urine samples were obtained from a healthy female volunteer around 30 years.

The following dosage forms containing the drugs were purchased from local Pharmacies:

-Allercet capsules, batch \# 820304, each capsule labeled to contain $30 \mathrm{mg}$ PSE and $10 \mathrm{mg}$ cetirizine $\mathrm{HCl}$, product of Global Napi Pharmaceuticals, 6th of October City-Giza-Egypt.

-Contaflu tablets, batch \# 061342, each tablet labeled to contain $24 \mathrm{mg}$ of PPA, $3 \mathrm{mg}$ of chlorpheniramine maleate and $200 \mathrm{mg}$ of propyphenazone, product of Egyptian Int. Pharmaceutical Industries CO. E.P.I.CO, $10^{\text {th }}$ of Ramadan City, Egypt.

-Ephedrine ampoule, batch \# 11, each ampoule (1 mL) labeled to contain $30 \mathrm{mg}$ of EPH, product of Chemical industries Development(CID)-Giza-A.R.E.

\subsection{Standard solutions}

Standard stock solutions of the studied drugs were prepared by dissolving $10.0 \mathrm{mg}$ of each of the studied drugs in $100 \mathrm{~mL}$ of distilled water. Serial dilution with the same solvent was performed to obtain the appropriate concentration range. These solutions were stable for at least 10 days when kept in the refrigerator and protected from light.

\subsection{General Analytical Procedures}

\subsubsection{Construction of the Calibration Curves}

Aliquot volumes of PPA, EPH and PSE standard solutions covering the working concentration ranges were transferred in to a series of screw capped test tubes, followed by specific volume of borate buffer at $\mathrm{pH}$ 8.0. Then, the specific volume of $3 \%(\mathrm{v} / \mathrm{v})$ of DNFB was added. The test tubes were heated in a thermostatically controlled water bath at $70^{\circ} \mathrm{C}$ in case of PSE and at $80^{\circ} \mathrm{C}$ in case of $\mathrm{EPH}$ and PPA, respectively. The solutions were heated for 25 min in case of PSE, EPH and for $20 \mathrm{~min}$ in case of PPA, respectively. The reaction was stopped by cooling under tap water, then $0.2 \mathrm{~mL}$ of concentrated $\mathrm{HCl}$ was added and the contents of the test tubes were then transferred in to $10 \mathrm{~mL}$ volumetric flasks, diluted to the volume with specific solvent and mixed well. The absorbance of the resulted product was measured at $370 \mathrm{~nm}$ in case of PPA and at $380 \mathrm{~nm}$ for EPH and PSE, respectively against a reagent blank prepared simultaneously. The absorbance of the resulted solution was plotted versus the final concentration of the drug $(\mu \mathrm{g} / \mathrm{mL})$ to obtain the calibration graphs. Alternatively, the corresponding regression equations were derived.

\subsubsection{Application of the Proposed Method to the Analysis of the Studied Drugs in their Dosage Forms - For tablets and capsules:}

An accurately weighed quantity of the mixed contents of ten capsules or powdered tablets equivalent to $10.0 \mathrm{mg}$ of PSE or PPA were transferred into conical flask and extracted with $3 \times 30 \mathrm{~mL}$ of distilled water in case of PSE and PPA, respectively by sonication for $30 \mathrm{~min}$. The solution was filtered into $100 \mathrm{~mL}$ volumetric flask and completed to the volume with the same solvent. Aliquots covering the working concentration ranges were analyzed as described under" Construction of the Calibration Curves". The concentrations of the drugs were determined using, either the calibration curves or the corresponding regression equations. 


\section{- For ephedrine Ampoules}

The contents of ten ephedrine ampoules were emptied and mixed well. An accurately measured volume of the resulting solution equivalent to $10.0 \mathrm{mg}$ of $\mathrm{EPH}$ was transferred into $100 \mathrm{~mL}$ volumetric flask, and diluted to volume with distilled water. Aliquots covering the working concentration ranges were analyzed as described under" Construction of the Calibration curve". The concentration of EPH was determined using, either the calibration curves or the corresponding regression equation.

\subsubsection{Application of the Proposed Method to the Analysis of PSE in spiked human urine}

Five $\mathrm{mL}$ of human urine were spiked with 20, 40, $60 \mu \mathrm{g} /$ $\mathrm{mL}$ of PSE were transferred into series of centrifugation tubes, the solutions were then rendered alkaline with $0.5 \mathrm{~mL}$ of $5 \mathrm{M} \mathrm{KOH}$ to liberate the base, followed by $3 \mathrm{~g}$ of $\mathrm{NaCl}$ as described by Avois et al [32]. The spiked urine is then extracted with three portions each of $2 \mathrm{~mL}$ of ter.-butyl methyl ether (TBME), centrifuged for 5 minutes at $2500 \mathrm{~g}$. After centrifugation, the clear supernatant was collected, evaporated till dryness under nitrogen gas. The residue was dissolved in $3 \mathrm{~mL}$ of distilled water and completed as described under "Construction of the Calibration Curve.

\section{Results and discussion}

2,4-dinitrofluorobenzene (DNFB) as an active aryl halide reacts with primary or secondary amine in aqueous alkaline medium to form a yellow colored product through a nucleophilic substitution reaction [33]. The presence of primary amine in PPA and secondary amine in both of PSE and EPH which are highly susceptible for derivatization reaction with DNFB initiated the present study. In the present study, the studied drugs were found to react with DNFB in borate buffer producing a yellow color peaking at $380 \mathrm{~nm}$ for EPH and PSE and at $370 \mathrm{~nm}$ for PPA, respectively (Figure 2).

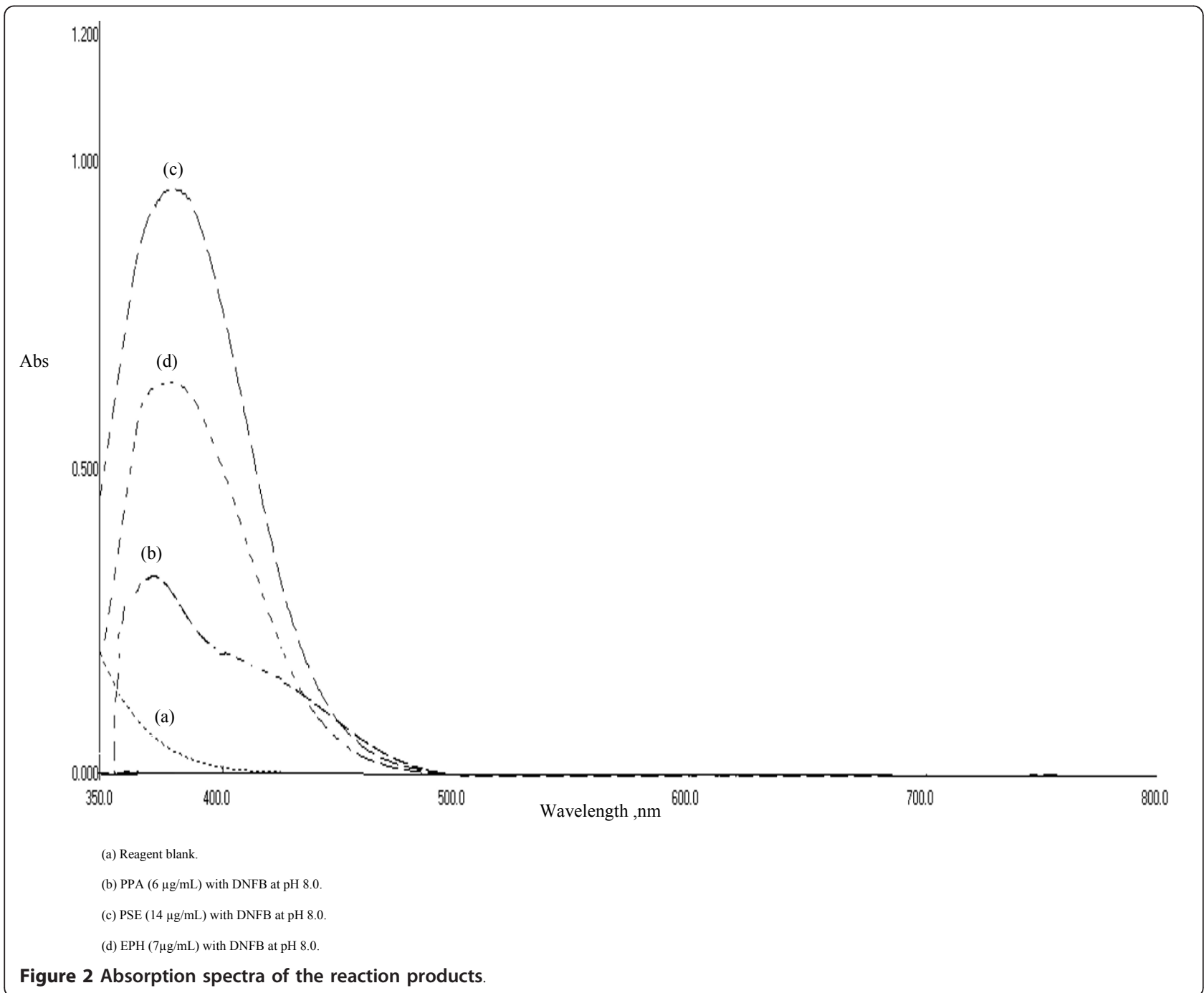




\subsubsection{Study of Experimental Parameters}

Experimental parameters affecting color development and its stability were carefully studied and optimized; each was changed while others were kept constant. Experimental parameters include; effect of $\mathrm{pH}$, volume of buffer solution, volume of DNFB solution, heating time, surface active agent (SAA), temperature and effect of diluting solvent.

\subsection{1.i. Effect of $\mathrm{pH}$}

The reaction between the investigated drugs and DNFB was investigated over the $\mathrm{pH}$ range of 7.0-9.0 using 0.2 $\mathrm{M}$ borate buffer. The reaction showed the highest absorbance value in borate buffer of $\mathrm{pH} 8.0 \pm 0.5$ for $\mathrm{EPH}$, PPA and PSE. Therefore, $\mathrm{pH} 8.0$ was selected as the optimum $\mathrm{pH}$ value throughout this study (Figure 3 ).

\subsection{1. ii. Effect of volume of buffer solution}

It was found that increasing the volume of $0.2 \mathrm{M}$ borate buffer produced a corresponding increase in the absorbance value of the reaction product up to $0.5 \mathrm{~mL}$ for PSE and $\mathrm{EPH}$ and $0.8 \mathrm{~mL}$ for PPA, and it remained constant up to $1.0 \mathrm{~mL}$ for PSE, $1.2 \mathrm{~mL}$ for PPA and $1.5 \mathrm{~mL}$ in case of EPH, respectively (Figure 4). Therefore, $0.8 \pm 0.2 \mathrm{~mL}$ for PSE, $1.0 \pm 0.2 \mathrm{~mL}$ for PPA and $1.0 \pm 0.5 \mathrm{~mL}$ for $\mathrm{EPH}$ were chosen as the optimum buffer volume for the analysis.

\subsection{1.iii. Effect of the volume of DNFB solution}

The influence of the volume of DNFB was studied using different volumes of $0.3 \%,(\mathrm{v} / \mathrm{v})$ solution of the reagent. It was found that increasing volumes of the reagent produced a proportional increase in the absorbance value up to $0.6 \mathrm{~mL}$ for PSE, $0.5 \mathrm{~mL}$ for PPA and $0.6 \mathrm{~mL}$ for EPH. However, no further increase in the absorbance value was achieved upon increasing the volume of the reagent up to $1.2 \mathrm{~mL}$ for PSE, $0.7 \mathrm{~mL}$ for PPA and $1.0 \mathrm{~mL}$ for EPH. Therefore, $0.8 \pm 0.2 \mathrm{~mL}$ for PSE, $0.6 \pm 0.1 \mathrm{~mL}$ for PPA and $0.8 \pm 0.2 \mathrm{~mL}$ for EPH of $0.3 \%$, (v/v) DNFB solution were chosen as the optimal volume of the reagent (Figure 5).

Upon the reaction of any of the studied drugs with DNFB a yellow colored product was attained along with the alkaline hydrolysis product of DNFB (2,4-dinitrophenolate), which exhibits an intense yellow color [30]. The spectra of the two products are overlapped rendering impossible measurement of the analyte derivative. However, upon acidification with conc. $\mathrm{HCl}$ after the completion of the reaction,

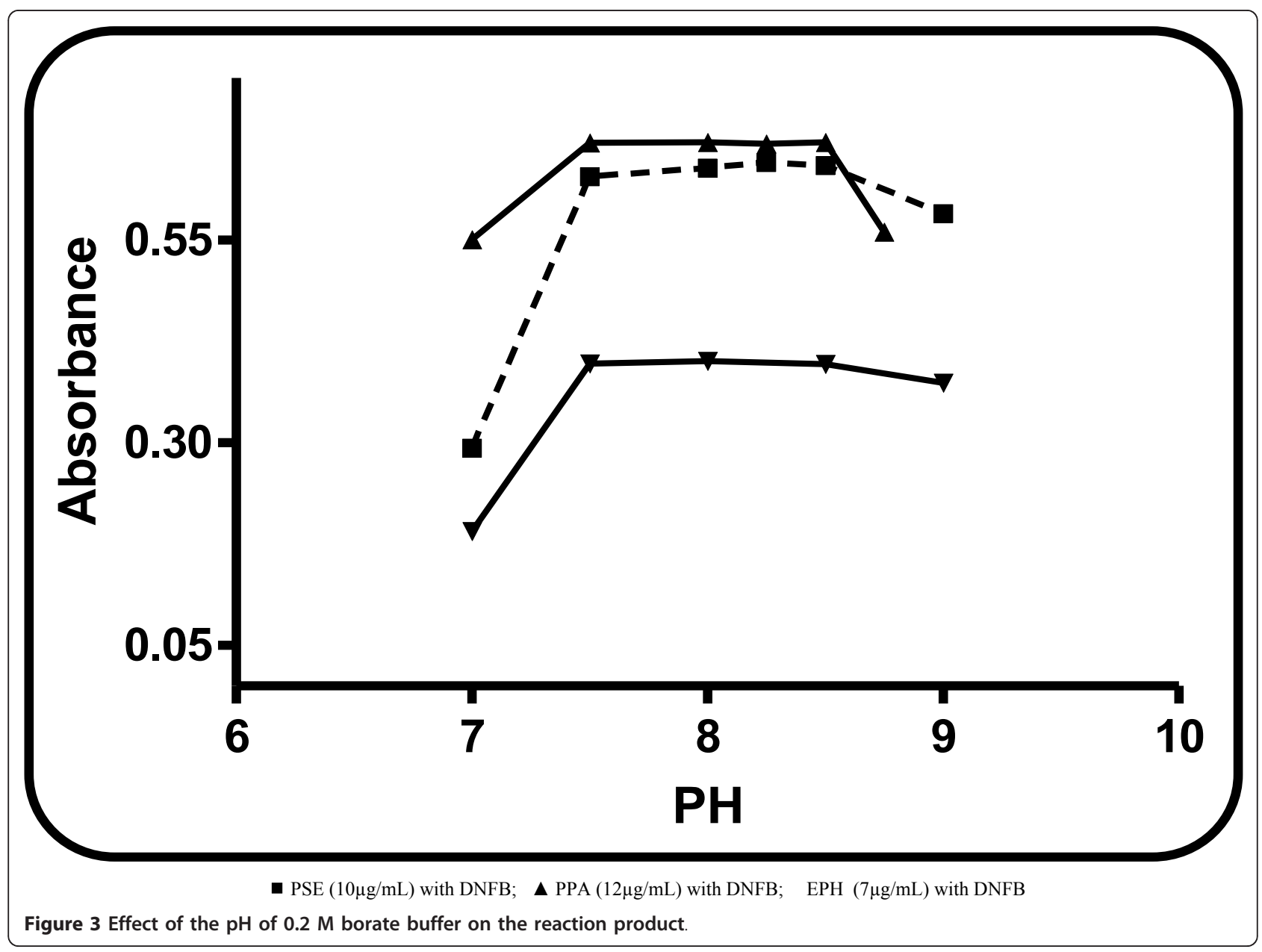




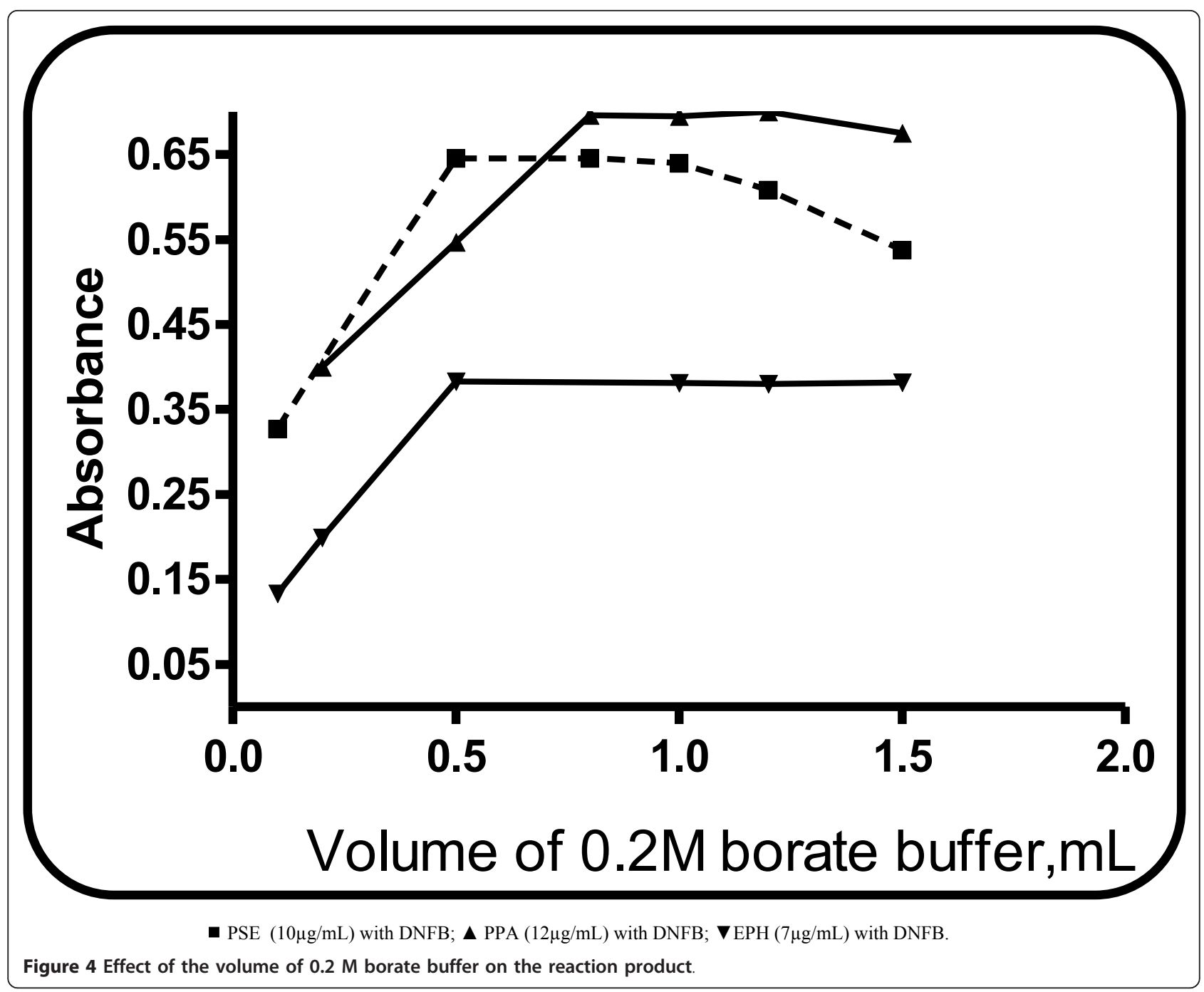

the yellow 2, 4-dinitrophenolate turns to the colorless 2, 4dinitrophenol, allowing the quantitative measurement of the Drug-DNFB derivative which remains stable up to $60 \mathrm{~min}[30]$.

\subsection{1. iv Effect of heating time}

The effect of the heating time of the reaction between the investigated drugs and DNFB was studied. Increasing the heating time resulted in gradual increase in the absorbance value of the reaction product up to $20 \mathrm{~min}$ for PSE, $15 \mathrm{~min}$ for PPA and $20 \mathrm{~min}$ for EPH, respectively, after which no further increase in the absorption intensities occur. Therefore $25 \pm 5 \mathrm{~min}$ for PSE, EPH and $20 \pm 5 \mathrm{~min}$ for PPA were chosen as the optimum buffer volume through this approach (Figure 6).

\subsection{1. v. Effect of heating temperature}

In order to obtain the highest and most stable absorbance, the effect of the reaction time and heating temperature was investigated (Figure 7). It was found that, the reaction proceeds very slowly at room temperature.
A gradual increase in the heating temperature produced a significant increase in the absorbance of the reaction product up to $70^{\circ} \mathrm{C}$ for PSE, $80^{\circ} \mathrm{C}$ for PPA and $\mathrm{EPH}$, respectively. Therefore, heating was achieved at $70^{\circ} \mathrm{C}$ for PSE, $80^{\circ} \mathrm{C}$ for PPA and $\mathrm{EPH}$, respectively.

\subsection{1. vi Effect of diluting solvent}

The effect of diluting solvent was tested using different solvents viz water, methanol, acetone, acetonitrile, dimethylformamide, dimethylsulfoxide and isopropanol. Using water as diluting solvent gave the highest absorbance value in case of PSE and PPA while in case of EPH; the maximum absorbance intensity was produced by using methanol as a diluting solvent. On the other hand, dilution with dimethylformamide and dimethylsulfoxide resulted in high back ground absorbance of the blank.

\subsection{1. vii Effect of surface active agent:-}

Each of $1 \%$, (w/v) SDS, 1\%, (w/v) cetrimide and 1\%, (w/v) tween were tested, hopefully they may increase the absorbance value of the reaction product. Unfortunately, no 


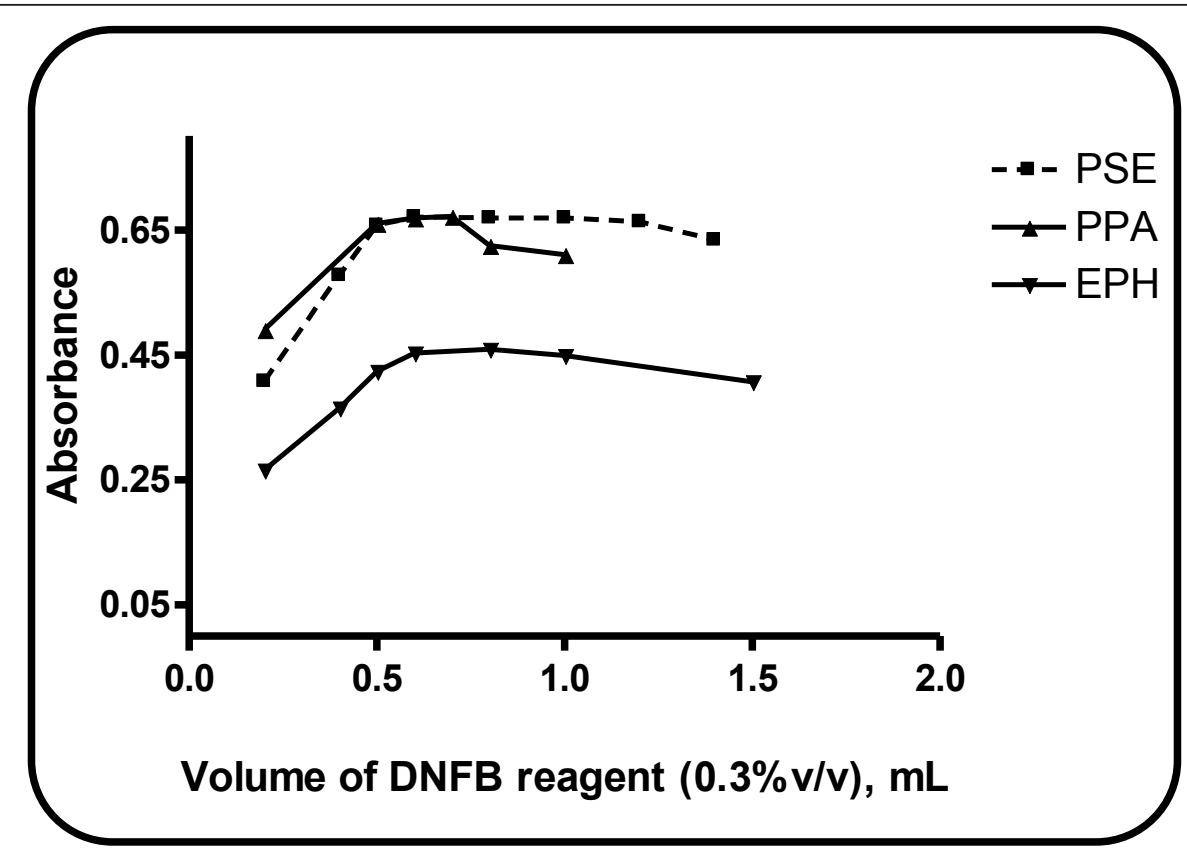

- PSE $(10 \mu \mathrm{g} / \mathrm{mL})$ with DNFB

$\Delta$ PPA $(12 \mu \mathrm{g} / \mathrm{mL})$ with DNFB

$\boldsymbol{\nabla} \mathrm{EPH}(7 \mu \mathrm{g} / \mathrm{mL})$ with DNFB

Figure 5 Effect of volume of reagent on the reaction product.

marked increase in the absorbance value was observed. Therefore, the reaction was carried out omitting SAA.

\subsection{1. viii Effect of time on the stability of the formed adduct}

The reaction product was found to be stable for at least $60 \mathrm{~min}$ at room temperature.

\subsection{Validation of the proposed Method}

The validity of the proposed methods was tested regarding linearity, specificity, accuracy, repeatability and precision according to ICH Q2 (R1) recommendations [34].

\subsubsection{Linearity}

The absorbance concentration plots were rectilinear over the ranges of 2-20 for PPA and 1-14 $\mu \mathrm{g} / \mathrm{mL}$ for both of EPH and PSE, respectively, cited in Table 1. The proposed method was evaluated for the accuracy as percent relative error (\% Er) and the precision as percent relative standard deviation (\% RSD) (Table 1).

Analysis of the data gave the following regression equations:

$$
\begin{aligned}
& \text { For PPA A }=0.0439+0.0496 C(r=0.9998) \\
& \text { For EPH A }=0.0049+0.0588 C(r=0.9999) \\
& \text { For PSE } A=0.0109+0.0633 C(r=0.9999)
\end{aligned}
$$

Where $\mathrm{A}$ is the Absorbance value
$\mathrm{C}$ is the concentration in $\mu \mathrm{g} / \mathrm{mL}$

$\mathrm{r}$ is the correlation coefficient

\subsubsection{Limit of quantitation and limit of detection}

The limits of quantitation (LOQ) and (LOD) were calculated according to ICH Q2 (R1) recommendation [34]. The results are shown in (Table 1).

LOQ and LOD were calculated according to the following equations [34]:

$$
\begin{aligned}
& \mathrm{LOQ}=10 \mathrm{~S}_{\mathrm{a}} / \mathrm{b} \\
& \mathrm{LOD}=3.3 \mathrm{~S}_{\mathrm{a}} / \mathrm{b}
\end{aligned}
$$

Where $S_{a}$ is the standard deviation of the intercept of regression line, and $b$ is the slope of the regression line.

\subsubsection{Accuracy}

To test the validity of the proposed method, it was applied to the determination of pure sample of PPA, EPH and PSE over the concentration ranges cited in (Table 2). The results obtained were in good agreement with those obtained using the comparison methods [35-37]. Statistical analysis of the results using Student $t$-test and the variance ratio F-test [38] revealed no significance differences between the performance of the proposed and comparison methods regarding the accuracy and precision, respectively (Table 2). The spectrophotometric comparison method [35] for PPA depends on its determination via reaction 

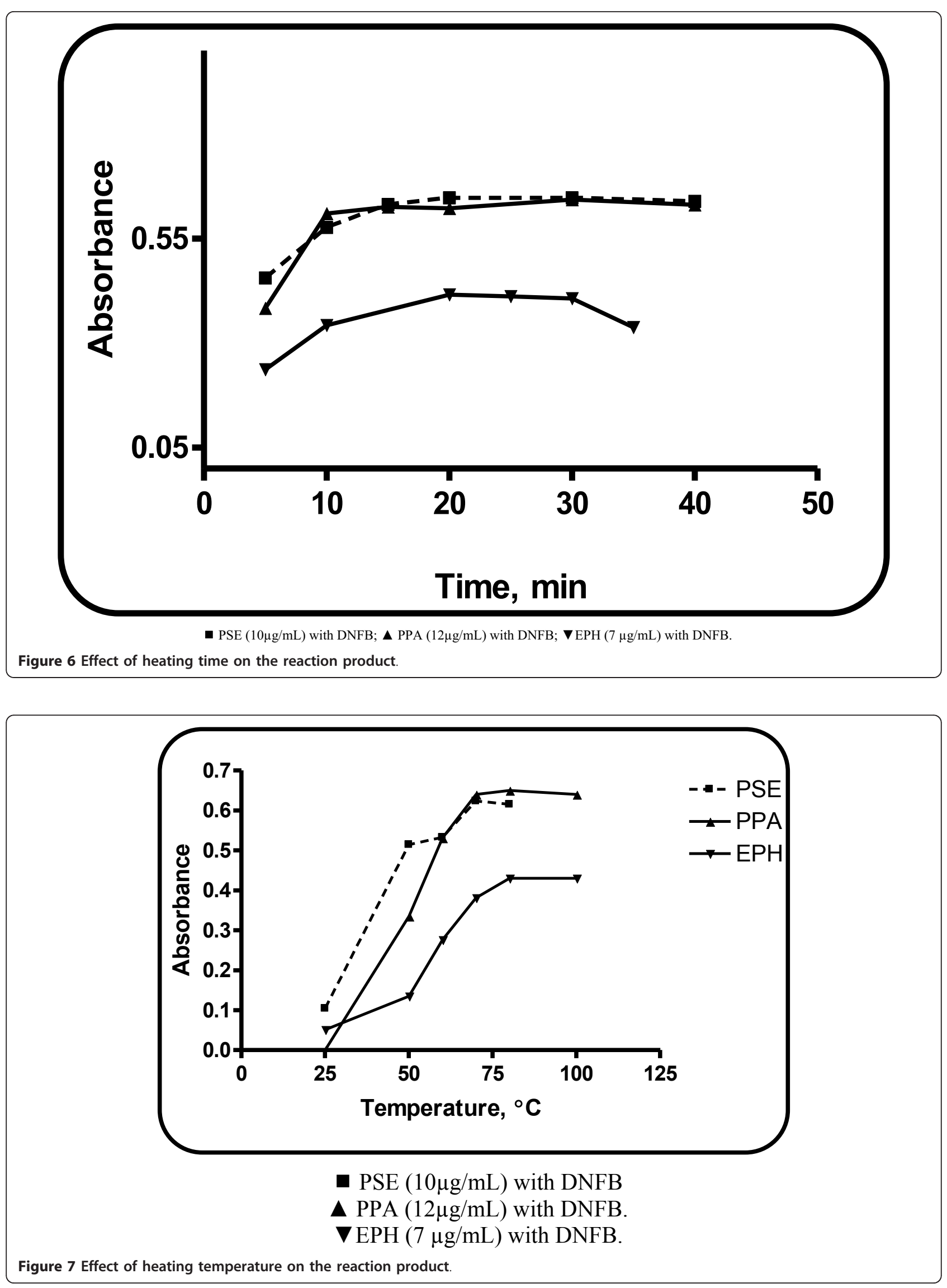
Table 1 Analytical performance data for the determination of the studied drugs by the proposed spectrophotometric method

\begin{tabular}{|c|c|c|c|}
\hline Parameter & PPA & EPH & PSE \\
\hline Linearity range $(\mu \mathrm{g} / \mathrm{mL})$ & $2-20$ & $1-14$ & $1-14$ \\
\hline Limit of detection, LOD, $(\mu \mathrm{g} / \mathrm{mL})$ & 0.20 & 0.13 & 0.20 \\
\hline Limit of quantification, $\mathrm{LOQ},(\mu \mathrm{g} / \mathrm{mL})$ & 0.60 & 0.40 & 0.59 \\
\hline Correlation coefficient $(r)$ & 0.9998 & 0.9999 & 0.9999 \\
\hline Slope & 0.050 & 0.059 & 0.063 \\
\hline Intercept & 0.044 & 0.005 & 0.011 \\
\hline S.D. of residuals, $S_{y / x}$ & $5.04 \times 10^{-3}$ & $3.00 \times 10^{-3}$ & $5.63 \times 10^{-3}$ \\
\hline S.D. of intercept, $S_{a}$ & $2.99 \times 10^{-3}$ & $2.36 \times 10^{-3}$ & $3.76 \times 10^{-3}$ \\
\hline S.D. of slope, $S_{b}$ & $3.00 \times 10^{-4}$ & $2.75 \times 10^{-4}$ & $4.71 \times 10^{-4}$ \\
\hline Percentage relative standered deviation, \% RSD & 1.08 & 0.96 & 0.99 \\
\hline Percentage error, \% Error & 0.41 & 0.34 & 0.40 \\
\hline Molar absorptivity, $\varepsilon$ L.moL ${ }^{1} . \mathrm{cm}^{1}$ & $9.3 \times 10^{3}$ & $1.43 \times 10^{4}$ & $1.55 \times 10^{4}$ \\
\hline
\end{tabular}

Table 2 Application of the proposed and comparison methods to the determination of the studied drugs in pure forms

\begin{tabular}{|c|c|c|c|c|}
\hline \multirow[t]{2}{*}{ Parameter } & \multicolumn{3}{|c|}{ proposed method } & \multirow{2}{*}{$\begin{array}{c}\begin{array}{c}\text { Comparison } \\
\text { method }^{(35)}\end{array} \\
\% \text { Found }^{\text {a }}\end{array}$} \\
\hline & $\begin{array}{c}\text { Conc.taken } \\
(\mu \mathrm{g} / \mathrm{mL})\end{array}$ & $\begin{array}{l}\text { Conc.found } \\
(\mu \mathrm{g} / \mathrm{mL})\end{array}$ & $\%$ Found $^{a}$ & \\
\hline \multirow[t]{7}{*}{ PPA } & 2.0 & 1.96 & 98.00 & \\
\hline & 4.0 & 4.01 & 100.25 & 99.53 \\
\hline & 6.0 & 5.97 & 99.50 & 102.01 \\
\hline & 10.0 & 10.07 & 100.70 & 100.11 \\
\hline & 12.0 & 12.13 & 101.08 & \\
\hline & 18.0 & 17.81 & 98.94 & \\
\hline & 20.0 & 20.07 & 100.35 & \\
\hline $\bar{x} \pm$ S.D. & & $99.83 \pm 1.08$ & & $100.55 \pm 1.29$ \\
\hline $\mathbf{t}$ & & $0.339(2.306)$ & & \\
\hline $\mathrm{F}$ & & $1.426(5.14)$ & & \\
\hline \multirow[t]{2}{*}{ Parameter } & & oposed method & & $\begin{array}{l}\text { Comparison } \\
\text { Method }^{(36)}\end{array}$ \\
\hline & $\begin{array}{l}\text { Conc. } \\
\text { taken } \\
(\mu \mathrm{g} / \mathrm{mL})\end{array}$ & $\begin{array}{c}\text { Conc. } \\
\text { found }(\mu \mathrm{g} / \mathrm{mL})\end{array}$ & $\%$ Found $^{\mathrm{a}}$ & $\%$ Found $^{\mathrm{a}}$ \\
\hline \multirow[t]{8}{*}{ EPH } & 1.0 & 1.02 & 102.00 & \\
\hline & 3.0 & 2.98 & 99.33 & \\
\hline & 5.0 & 5.02 & 100.40 & 102.00 \\
\hline & 7.0 & 6.94 & 99.14 & 99.98 \\
\hline & 8.0 & 7.98 & 99.75 & 101.05 \\
\hline & 9.0 & 9.10 & 101.11 & \\
\hline & 10.0 & 9.98 & 99.80 & \\
\hline & 14.0 & 13.99 & 99.93 & \\
\hline $\bar{x} \pm$ S.D. & & $100.18 \pm 0.96$ & & $100.01 \pm 1.01$ \\
\hline $\mathbf{t}$ & & $1.264(2.262)$ & & \\
\hline $\mathrm{F}$ & & $1.106(4.74)$ & & \\
\hline \multirow[t]{2}{*}{ Parameter } & & oposed method & & $\begin{array}{l}\text { Comparison } \\
\text { Method }^{(37)}\end{array}$ \\
\hline & $\begin{array}{c}\text { Conc. } \\
\text { taken } \\
(\mu \mathrm{g} / \mathrm{mL})\end{array}$ & $\begin{array}{c}\text { Conc. } \\
\text { found } \\
(\mu \mathrm{g} / \mathrm{mL})\end{array}$ & $\%$ Found $^{a}$ & $\%$ Found $^{a}$ \\
\hline
\end{tabular}


Table 2 Application of the proposed and comparison methods to the determination of the studied drugs in pure forms (Continued)

\begin{tabular}{ccccc}
\hline PSE & 1.0 & 1.01 & 101.00 & 102.00 \\
& 3.0 & 3.00 & 100.00 & 98.33 \\
\\
& 4.0 & 3.94 & 98.50 & 100.60 \\
\\
10.0 & 10.06 & 100.83 & \\
& 12.0 & 12.10 & 99.21 & $99.45 \pm 2.22$ \\
$\mathbf{x} \pm$ S.D. & 14.0 & 13.89 & & \\
$\mathbf{t}$ & & $100.02 \pm 0.99$ & & \\
$\mathbf{F}$ & & $0.597(2.365)$ & & \\
\hline
\end{tabular}

a Each result is the average of three separate determinations.

*Values between parentheses are the tabulated $t$ and $F$ values, at $p 0.05^{(38)}$.

with NBD-Cl and measuring the absorbance of the reaction product at $455 \mathrm{~nm}$. The comparison method for $\mathrm{EPH}$ [36] was through Charge transfer reaction using p-chloranil and acetaldehyde and measuring the absorbance of the reaction product at $680 \mathrm{~nm}$. On the other hand, the comparison method for PSE was based on measuring first derivative ratio derivative of PSE in $0.1 \mathrm{~N} \mathrm{HCl} \mathrm{[37].}$

The validity of the methods was proved by statistical evaluation of the regression line, using the standard deviation of the residuals $\left(S_{y / x}\right)$, the standard deviation of the intercept $\left(S_{a}\right)$ and standard deviation of the slope $\left(S_{b}\right)$. The results are abridged in (Table 1 ). The small values of the figures indicate low scattering of the calibration points around the calibration line and high precision.

\subsubsection{Precision}

3.2.4.i. Repeatability: the repeatability was performed through replicate analysis of three concentrations of the three drugs over the specified working concentration range in pure form on three successive occasions. The results are presented in (Table 3 ).

3.2.4.ii. Intermediate precision: intermediate precision was tested by replicate analysis of the three drugs in pure form using the concentrations shown in (Table 3) for a period of 3 successive days. The results are summarized in (Table 3).

Table 3 Accuracy and precision data for the determination of the studied drugs by the proposed spectrophotometric method

\begin{tabular}{|c|c|c|c|c|c|c|}
\hline \multirow[t]{2}{*}{ Parameter } & \multicolumn{3}{|c|}{ Intra-day precision } & \multicolumn{3}{|c|}{ Inter-day precision } \\
\hline & $\begin{array}{l}\text { Conc. taken } \\
(\mu \mathrm{g} / \mathrm{mL})\end{array}$ & $\begin{array}{l}\text { Conc. } \\
\text { found } \\
(\mu \mathrm{g} / \mathrm{mL})\end{array}$ & $\%$ Found & $\begin{array}{l}\text { Conc. } \\
\text { taken } \\
(\mu \mathrm{g} / \mathrm{mL})\end{array}$ & $\begin{array}{l}\text { Conc. } \\
\text { found } \\
(\mu \mathrm{g} / \mathrm{mL})\end{array}$ & $\%$ Found \\
\hline \multirow[t]{3}{*}{ PPA } & 4.0 & 4.03 & 100.75 & 4.0 & 3.97 & 99.25 \\
\hline & 6.0 & 5.98 & 99.67 & 6.0 & 5.88 & 98.00 \\
\hline & 10.0 & 10.00 & 100.00 & 10.0 & 9.80 & 98.00 \\
\hline $\bar{x} \pm \mathrm{SD}$ & & $100.14 \pm 0.55$ & & & $98.42 \pm 0.72$ & \\
\hline \%RSD & & 0.55 & & & 0.73 & \\
\hline$\%$ Er & & 0.32 & & & 0.42 & \\
\hline \multirow[t]{3}{*}{ EPH } & 7.0 & 6.98 & 99.71 & 7.0 & 7.07 & 101.00 \\
\hline & 8.0 & 8.12 & 101.50 & 8.0 & 8.09 & 101.12 \\
\hline & 10.0 & 10.02 & 100.20 & 9.0 & 9.15 & 101.67 \\
\hline $\bar{x} \pm \mathrm{SD}$ & & $100.47 \pm 0.92$ & & & $101.26 \pm 0.36$ & \\
\hline \%RSD & & 0.91 & & & 0.35 & \\
\hline$\% \mathrm{Er}$ & & 0.52 & & & 0.20 & \\
\hline \multirow[t]{3}{*}{ PSE } & 6.0 & 6.12 & $102.00^{*}$ & 6.0 & 5.96 & 99.33 \\
\hline & 10.0 & 10.23 & 102.30 & 10.0 & 10.07 & 100.70 \\
\hline & 12.0 & 12.29 & 102.42 & 12.0 & 12.09 & 100.75 \\
\hline $\bar{x} \pm \mathrm{SD}$ & & $102.24 \pm 0.22$ & & & $100.26 \pm 0.80$ & \\
\hline \%RSD & & 0.21 & & & 0.80 & \\
\hline$\% \mathrm{Er}$ & & 0.12 & & & 0.46 & \\
\hline
\end{tabular}

* Each result is the average of three separate determinations. 


\subsubsection{Robustness of the method}

The robustness of the proposed method was examined by evaluating the influence of small, deliberate variations in the method variables on the absorbance of the reaction product. The tested variables included; the $\mathrm{pH} 8.0 \pm 0.5$ for the three studied drugs, the change in the volume of the buffer solution $0.8 \pm 0.2 \mathrm{~mL}$ for PSE, $1.0 \pm 0.2 \mathrm{~mL}$ and $1.0 \pm 0.5 \mathrm{~mL}$ for PPA. The change in the volume of DNFB $0.3 \%,(\mathrm{v} / \mathrm{v}), 0.8 \pm 0.2 \mathrm{~mL}$ for PSE, $0.6 \pm 0.1 \mathrm{~mL}$ for PPA and $0.8 \pm 0.2$ for $\mathrm{EPH}$, the change in the heating time, $25 \pm$ $5 \mathrm{~min}$ for PSE and EPH and $20 \pm 5 \mathrm{~min}$ for PPA. These minor changes that may take place during the experimental operation didn't affect the absorbance of the reaction product.

\subsubsection{Selectivity}

The selectivity of the method was investigated by observing any interference encountered from the common tablet excipients such as talc, starch, magnesium stearate and avicil. These excipients didn't interfere with proposed method (Table 4).

\subsubsection{Specificity}

The proposed method is specific for the determination of EPH in the presence of its metabolite (deaminated form), since the latter is devoid from secondary aliphatic amine which is essential for the reaction with DNFB.

\subsection{Pharmaceutical Applications}

The proposed method was successfully applied for determination of the studied drugs in their pharmaceutical preparations. The results obtained were statistically compared to those of the comparison methods [35-37]. Using student's $t$-test for accuracy and the variance ratio F-test for precision as recorded in (Table 4) revealed no significance difference in the performance of the two methods, respectively.

Table 4 Application of the proposed and comparison methods to the determination of the studied drugs in dosage form

\begin{tabular}{|c|c|c|c|}
\hline \multirow[t]{2}{*}{ Parameter } & \multicolumn{2}{|c|}{ The proposed method } & \multirow{2}{*}{$\begin{array}{c}\text { Comparison method }^{(35)} \\
\% \text { Found }\end{array}$} \\
\hline & $\begin{array}{c}\text { Conc. } \\
\text { taken } \\
(\mu \mathrm{g} / \mathrm{mL})\end{array}$ & $\%$ Found $^{a}$ & \\
\hline \multirow{3}{*}{$\begin{array}{c}\text { Contaflu tablets }^{\mathbf{c}} \\
\text { (24 mg of PPA, } 3 \mathrm{mg} \text { of chlorpheniramine maleate and } 200 \mathrm{mg} \text { of propyphenazone/tablet) }\end{array}$} & 8.0 & 99.92 & $99.77^{(35)}$ \\
\hline & 12.0 & 99.47 & 99.36 \\
\hline & 14.0 & 99.87 & 100.60 \\
\hline $\bar{x} \pm$ S.D. & 99.7 & \pm 0.25 & $99.91 \pm 0.63$ \\
\hline $\mathrm{T}$ & \multicolumn{3}{|c|}{$0.588(2.776)^{*}$} \\
\hline $\mathbf{F}$ & \multicolumn{3}{|c|}{$6.350(19.00)^{*}$} \\
\hline \multirow[t]{3}{*}{$\begin{array}{l}\text { Ephedrine mpoule } \\
\text { (30 mg of EPH/Ampoule) }\end{array}$} & 7.0 & 100.57 & $100.73^{(36)}$ \\
\hline & 8.0 & 100.87 & 101.44 \\
\hline & 10.0 & 101.91 & 102.36 \\
\hline $\bar{x} \pm$ S.D. & 101 & \pm 0.70 & $100.51 \pm 0.82$ \\
\hline $\mathbf{T}$ & \multicolumn{3}{|c|}{$0.647(2.776)^{*}$} \\
\hline F & \multicolumn{3}{|c|}{$1.372(19.00)^{*}$} \\
\hline \multirow[t]{3}{*}{$\begin{array}{c}\text { Allercet }^{\circledR} \text { capsule }^{\mathbf{b}} \\
\text { (30 mg PSE and } 10 \text { mg cetirizine HCl/capsule) }\end{array}$} & 6.0 & 100.18 & $100.98^{(37)}$ \\
\hline & 10.0 & 101.40 & 99.56 \\
\hline & 12.0 & 102.04 & 102.15 \\
\hline $\bar{x} \pm$ S.D. & 101 & \pm 0.94 & $100.90 \pm 1.30$ \\
\hline $\mathbf{t}$ & \multicolumn{3}{|c|}{$0.334(2.776)^{*}$} \\
\hline $\mathbf{F}$ & \multicolumn{3}{|c|}{$1.913(19.00)^{*}$} \\
\hline
\end{tabular}

a Each result is the average of three separate determinations.

*Values between parentheses are the tabulated $t$ and $F$ values, at $p 0.05^{(38)}$.

a Contaflu tablets, batch \# 061342, each tablet labeled to contain $24 \mathrm{mg}$ of phenylpropanolamine $\mathrm{HCl}, 3 \mathrm{mg}$ of chlorpheniramine maleate and $200 \mathrm{mg}$ of propyphenazone, product of Egyptian Int..Pharmaceutical Industries CO. E.P.I.CO, $10^{\text {th }}$ of Ramadan City, Egypt.

${ }^{\mathrm{b}}$ Ephedrine ampoule:-batch \# 11 each ampoule $(1 \mathrm{~mL})$ labeled to contain $30 \mathrm{mg}$ of ephedrine $\mathrm{HCl}$, A product of Chemical industries Development(CID)-Giza-A.R. E.

c Allercet capsule, batch \# 820304, each capsule labeled to contain 30 mg pseudoephedrine $\mathrm{HCl}$ and 10 mg cetirizine $\mathrm{HCl}$, product of Global Napi Pharmaceuticals, $6^{\text {th }}$ of October City-Giza-Egypt.

d PPA content found in Contaflu tablet was found to be $23.94 \mathrm{mg} / \mathrm{tablet}$.

e EPH content found in Ephedrine ampoule was found to be $30.34 \mathrm{mg} / \mathrm{ampoule}$.

${ }^{f}$ PSE content found in Allercet ${ }^{\mathbb{R}}$ capsule was found to be $30.36 \mathrm{mg} / \mathrm{capsule}$. 


\subsection{Biological analysis}

Upon oral administration of $30 \mathrm{mg}$ of PSE, it was found that up to about $90 \%$ of the dose is excreted unchanged in the urine in 24 hours with less than $1 \%$ as norpseudoephedrine (cathine) [39]. This initiated the present study. Such concentration lies within the working concentration range of the present study.

Therefore, the proposed method was applied for the determination of PSE in spiked human urine. The extraction adopted by Avois et al [32] was applied here (Table 5).

\subsection{Molar ratio and mechanism of the reaction}

The stoichiometry of the reaction was studied adopting the limiting logarithmic method [40]. Plots of log absorbance versus log [DNFB] and log [Drug] gave two straight lines, the slopes of which were $0.57 / 0.78$ for DNFB/PPA, 0.41/0.37 for DNFB/EPH and 0.72/0.94 for DNFB/PSE (Figure 8). Hence, it was concluded that the reaction proceeds in the ratio of $1: 1$, confirming that one molecule of the drug condenses with one molecule of DNFB. Based on the observed molar ratio and by analogy to previous reports [28], the mechanism of the reaction is postulated to proceed as shown in the following scheme 1.

\section{Conclusion}

The proposed spectrophotometric method provided simple, reproducible and accurate method for determination of PSE, PPA and EPH. The established method was validated and applied to determination of the studied drugs in their dosage forms without interference from common excipients. The developed method showed to be a simple and suitable technique to quantify these drugs and might be employed for quality control analysis.

Table 5 Application of the proposed method to the determination of PSE in spiked human urine

\begin{tabular}{cccc}
\hline Parameter & $\begin{array}{c}\text { Amount added } \\
(\boldsymbol{\mu} \mathbf{g} / \mathbf{m L})\end{array}$ & $\begin{array}{c}\text { Amount found } \\
(\boldsymbol{\mu} \mathbf{g} / \mathbf{m L})\end{array}$ & Recovery\% \\
\hline Spiked urine sample & 2.0 & 2.15 & 107.50 \\
& 4.0 & 4.28 & 107.00 \\
& 6.0 & 6.60 & 110.00 \\
Mean found, $\bar{x}$ & & 108.17 & \\
\pm S.D & & 1.60 & \\
\% RSD & & 1.48 & \\
\% Error & & 0.85 & \\
\hline
\end{tabular}

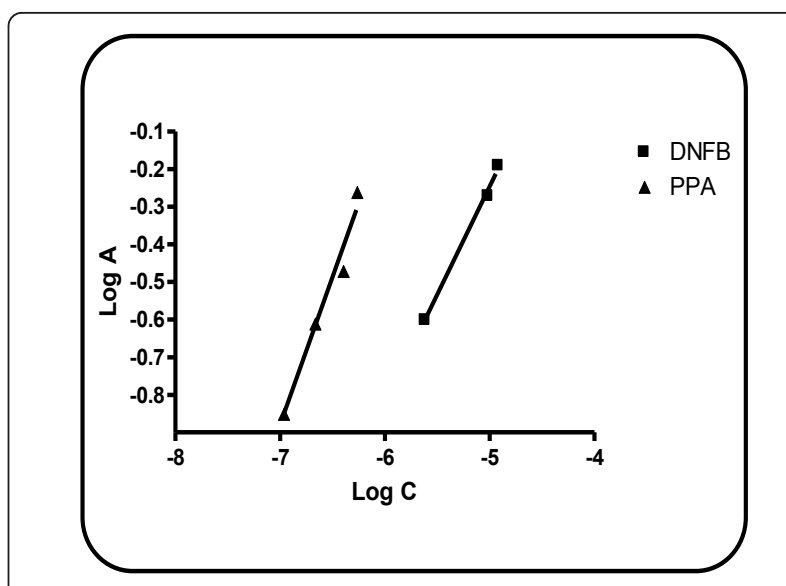

(A)PPA with DNFB

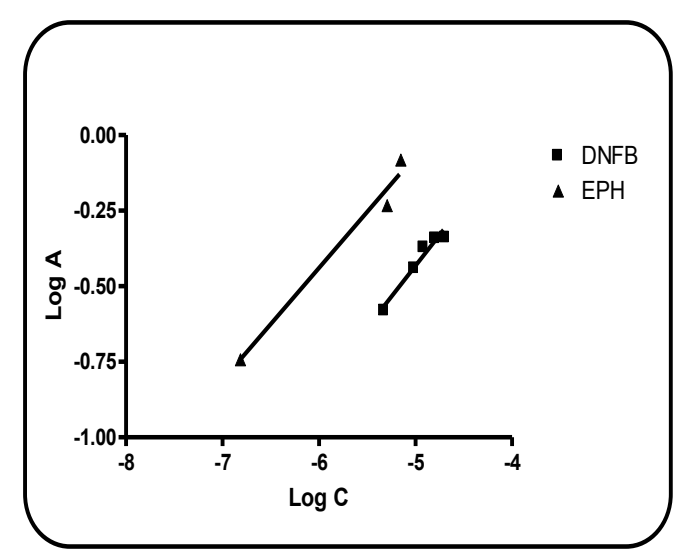

(B)EPH with DNFB

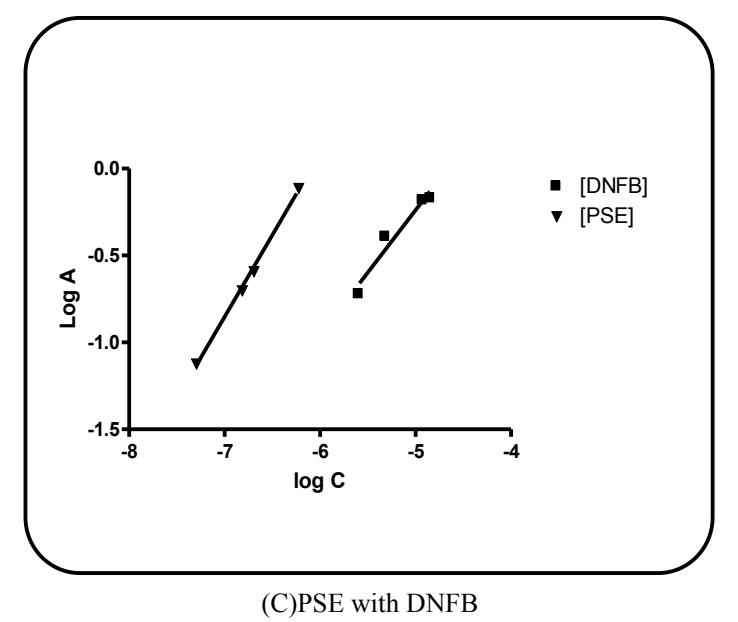

Figure 8 Limiting logarithmic plots for the molar reactivity.

Authors' contributions

MIW designed the proposed method. NME coordinated the study and modified the text. SS carried out the experimental work and analyzed the data statistically. All authors read and approved the final manuscript. 


\section{Competing interests}

The authors declare that they have no competing interests.

Received: 27 June 2011 Accepted: 27 October 2011

Published: 27 October 2011

\section{References}

1. Sweetman S: Martindale: The Complete Drug Reference The pharmaceutical Press: London; 2007, Electronic version.

2. United States Pharmacopeial Convention: The United States Pharmacopoeid 30th and The National formulary 25th Rockville, MD, USA: United States Pharmacopeial; 2007, Electronic Version.

3. British Pharmacopoeia Commission: The British Pharmacopoeia 2007 Her Majesty's Stationary Office, London; 2006, Electronic Version.

4. Kanfer I, Haigh JM, Dowse R: Chapter 10 Phenylpropanolamine Hydrochloride. In Analytical Profiles of Drug Substances. Volume 12. Academic Press: Massachusetts, USA; 1982:357-384.

5. Issa YM, Youssef AF, Mutair AA: Conductimetric determination of phenylpropanolamine $\mathrm{HCl}$, ranitidine $\mathrm{HCl}$, hyoscyamine $\mathrm{HBr}$ and betaine $\mathrm{HCl}$ in their pure state and pharmaceutical preparations. Farmaco 2005, 60:541-6.

6. Walash Ml, EL-Enany N, Saad S: A New Spectrophotometric Method for Determination of Phenylpropanolamine $\mathrm{HCl}$ in its Pharmaceutical Formulations via Reaction with 2,3,5,6-tetrachloro-1,4-benzoquinone. Int J Biomed Sci 2010, 6:151-7.

7. Shankle LL: Determination of phenylpropanolamine salts in dosage forms through fluorescent derivative formation. J Pharm Sci 1978, 67:1635-1636.

8. Kaddoumi A, Mori T, Nakashima MN, Wada M, Nakashima K: High performance liquid chromatography with fluorescence detection for the determination of phenylpropanolamine in human plasma and rat's blood and brain microdialysates using DIB-Cl as a label. J Pharm Biomed Anal 2004, 34:643-50

9. Azhagvuel S, Sekar R: Method development and validation for the simultaneous determination of cetirizine dihydrochloride, paracetamol, and phenylpropanolamine hydrochloride in tablets by capillary zone electrophoresis. J Pharm Biomed Anal 2007, 43:873-8.

10. Issa YM, Khalil MM, Zayed SIM, Hussein A: Flow injection potentiometric sensor for determination of phenylpropanolamine hydrochloride. Arabian J chem 2009, 2:41-46.

11. Abbasi K, Bhanger Ml, Khuhawar MY: Capillary gas chromatographic determination of phenylpropanolamine in pharmaceutical preparation. J Pharm Biomed Anal 2006, 41:998-1001.

12. British Pharmacopoeia Commission: The British Pharmacopoeia $2010 \mathrm{Her}$ Majesty's Stationary Office, London; 2010, Electronic Version.

13. Ali SL: Ephedrine Hydrochloride. In Profiles of Drug Substances, Excipients and Related. Volume 15. Methodology. Academic Press: Massachusetts, USA; 1986:233-282.

14. Marciniec B, Ogrodowczyk M: Direct determination of theophylline, ephedrine hydrochloride and phenobarbital in mixture. J Chem Anal 2002, 47:283-288.

15. Shao SM, Y S SM, Li JQ: Determination of ephedrine in Zhikepingchuan oral solutions. Yaowu-Fenxi-Zazhi 2001, 21:445-46.

16. Khveshchuk PF: Use of derivative spectrofluorimetry to estimate pyridoxine hydrochloride and ephedrine hydrochloride. Farmatsiya (Moscow) 1988, 37(3):7-41.

17. Nikolelis DP, Siontorou CG, Theoharis G, Bitter I: Flow injection analysis of mixtures of dopamine, adrenaline and ephedrine in human biofluids using stabilized after storage in air lipid membranes with a novel incorporated resorcin[4]arene receptor. Electroanal 2005, 17:887-894.

18. lio R, Chinaka S, Takayama N, Hayakawa K: Simultaneous chiral analysis of methamphetamine and related compounds by capillary electrophoresis/ mass spectrometry using anionic cyclodextrin. Anal Sci 2005, 21:15-9.

19. Mit'kina LI, Zaitseva II: Development of methods for qualitative analysis of Dixafen solution for injection. Khim. Farm Zh 1992, 26:74-76.

20. Roman MC: Determination of ephedrine alkaloids in botanicals and dietary supplements by HPLC-UV: collaborative study. J AOAC Int 2004, 87:1-14.

21. Wang M, Marriott PJ, Chan WH, Lee AW, Huie CW: Enantiomeric separation and quantification of ephedrine-type alkaloids in herbal materials by comprehensive two-dimensional gas chromatography. $J$ Chromatogr A 2006, 1112:361-8.

22. Benzara SA, McRae JW: Chapter 15 Pseudoephedrine Hydrochloride. In Analytical Profiles of Drug Substances. Volume 8. Academic Press: Massachusetts, USA; 1979:489-508.

23. Palabiyik I, Dinç E, Onur F: Simultaneous spectrophotometric determination of Pseudoephedrine hydrochloride and ibuprofen in a pharmaceutical preparation using ratio spectra derivative Spectrophotometry and multivariate calibration techniques. J Biomed Pharm Anal 2004, 34:473-83.

24. Luo JW, Zhu HL, Li HL: Study on characteristics of bias caused by flow injection-capillary electrophoresis with split-flow electrokinetic injection. Sepu 2005, 23:189-92.

25. Zhang L, Wang R, Yu Y, Zhang Y: Capillary electrophoresis with laserinduced fluorescence and pre-column derivatization for the analysis of illicit drugs. J Chromatogr B Analyt Technol Biomed Life Sci 2007, 857:130-5.

26. Makhija SN, Vavia PR: Stability indicating HPTLC method for the simultaneous determination of pseudoephedrine and cetirizine in pharmaceutical formulations. J Pharm Biomed Anal 2001, 25:663-7.

27. Hadad GM, Emara S, Mahmoud WMM: Development and validation of a stability-indicating RP-HPLC method for the determination of paracetamol with dantrolene or/and cetirizine and pseudoephedrine in two pharmaceutical dosage forms. Talanta 2009, 79:1360-7.

28. El-Enany N, El-Sherbiny D, Belal F: Spectrophotometric, spectrofluorometric and HPLC determination of desloratadine in dosage forms and human plasma. Chem Pharm Bull (Tokyo) 2007, 55:1662-70.

29. Abdel Razak O, Belal SF, Bedair MM, Barakat NS, Haggag RS: Spectrophotometric and polarographic determination of enalapril and lisinopril using 2,4-dinitrofluorobenzene. J Pharm Biomed Anal 2003, 31:701-11

30. Paraskevas G, Atta-Politou J, Koupparis M: Spectrophotometric determination of lisinopril in tablets using 1-fluoro-2,4-dinitrobenzene reagent. J Pharm Biomed Anal 2002, 29:865-72.

31. Jalalizadeh H, Souri E, Tehrani MB, Jahangiri A: Validated HPLC method for the determination of gabapentin in human plasma using pre-column derivatization with 1-fluoro-2,4-dinitrobenzene and its application to a pharmacokinetic study. J Chromatogr B Analyt Technol Biomed Life Sci 2007, 854:43-7.

32. Mateus-Avois L, Mangin P, Saugy M: Development and validation of a capillary zone electrophoresis method for the determination of ephedrine and related compounds in urine without extraction. $J$ Chromatogr B Analyt Technol Biomed Life Sci 2003, 791:203-16.

33. Connors KA, Ed: Reaction Mechanisms in Organic Analytical Chemistry Wiley: New York, USA; 1973, 274.

34. ICH Harmonized Tripartite Guideline, Validation of Analytical Procedures: Text and Methodology Q2(R1). Current Step 4 Version, Parent Guidelines on Methodology Dated November 6, 1996, Incorporated in November 2005 [http://www.ich.org/fileadmin/Public_Web_Site/ICH_Products/Guidelines/ Quality/Q2_R1/Step4/Q2_R1_Guideline.pdf], accessed February 15, 2008.

35. Street KW Jr, Abrenica MB: Spectrophotometric Determination of Phenyxpropanolamine Hydrochloride in Pharmaceuticals after Derivatization with NBD-C1. Anal Lett 1986, 19:597-614.

36. Amer MM, Taha AM, El-Shabouri SR, Khashaba PY: Spectrophotometric determination of ephedrine hydrochloride and phenylephrine hydrochloride. J Assoc Off Anal Chem 1982, 65:894-8.

37. El-Yazbi FA, Gazy AA, Mahgoub H, El-Sayed MA, Youssef RM: Spectrophotometric determination of binary mixtures of pseudoephedrine with some histamine $\mathrm{H} 1$-receptor antagonists using derivative ratio spectrum method. J Pharm Biomed Anal 2003, 31:801-809.

38. Miller JC, Miller JN: Statistics and Chemometrics for Analytical Chemistry. 5 edition. Pearson Education Limited: Harlow, England; 2005, 256.

39. Moffat AC: Clarke's Analysis of Drugs and Poisons The Pharmaceutical Press: London; 2006, Electronic version.

40. Rose J: Advanced Physico-Chemical Experiments Pitman, London; 1964.

doi:10.1186/1752-153X-5-65

Cite this article as: Walash et al:: Spectrophotometric determination of certain CNS stimulants in dosage forms and spiked human urine via derivatization with 2,4-Dinitrofluorobenzene. Chemistry Central Journal 2011 5:65. 